\title{
Hydrogeology

\section{An analytical methodology to estimate the changes in fresh groundwater resources with sea-level rise and coastal erosion in strip-island unconfined aquifers: illustration with Savary Island, Canada}

\begin{tabular}{|r|l|}
\hline Journal: & Hydrogeology Journal \\
\hline Manuscript ID & HJ-2020-6785.R2 \\
\hline Category: & Technical Note \\
\hline Date Submitted by the \\
Author: & n/a \\
\hline Complete List of Authors: & $\begin{array}{l}\text { Chesnaux, Romain; Université du Québec à Chicoutimi, Applied Sciences } \\
\text { Marion, Damien; Université du Québec à Chicoutimi, Applied Sciences } \\
\text { Boumaiza, Lamine; Université du Québec à Chicoutimi, Applied Sciences } \\
\text { Richard, Sandra; GWsolutions inc. } \\
\text { Walter, Julien; University of Quebec at Chicoutimi, Applied Sciences }\end{array}$ \\
\hline Keywords: & $\begin{array}{l}\text { climate change, island hydrology, groundwater resources, analytical } \\
\text { solutions, sea-level rise }\end{array}$ \\
\hline &
\end{tabular}

\section{SCHOLARONE ${ }^{\text {M }}$ \\ Manuscripts}


An analytical methodology to estimate the changes in fresh groundwater

resources with sea-level rise and coastal erosion in strip-island unconfined aquifers: illustration with Savary Island, Canada

R. Chesnaux*1, Marion, D. ${ }^{1}$, Boumaiza, L. ${ }^{1}$, Richard, S. ${ }^{2}$ and Walter, J. ${ }^{1}$

Université du Québec à Chicoutimi

Dept. of Applied Sciences

555, Boulevard de l'université

Saguenay, Quebec, Canada G7H 2B1

10

11

${ }^{1}$ Université du Québec à Chicoutimi, Centre d'études sur les ressources minérales, Groupe de recherche Risque Ressource Eau, Chicoutimi, Québec, Canada

13

${ }^{2}$ GW Solutions inc., Nanaimo, British Columbia, Canada

*corresponding author

Ph: 418-545-5011 \# 5426

E-mail: romain_chesnaux@uqac.ca 
1

\section{Abstract}

Closed-form analytical solutions for assessing the consequences of climate change on fresh groundwater oceanic island lenses have been developed by hydrogeologists during the last decade. Based on existing equations, this study focuses on the case of strip oceanic islands when three combined effects of climate change are observed to affect the freshwater lens volume and its groundwater resource renewal: sea-level rise, erosion, and change in groundwater recharge rates. New equations, integrating these combined effects of climate change on fresh groundwater resources are provided. These equations are solved by a novel methodology based on a Dupuit-Forchheimer groundwater flow model that allows for determination of the hydrogeological parameters included in the equations. The approach is illustrated with the strip island of Savary, which is located along the Pacific coast of Canada in the province of British Columbia. This example illustrates, on the one hand, the volume depletion of the island freshwater lens and, on the other hand, the decrease of the renewal rate of groundwater. The proposed approach can be applied to any strip islands worldwide to assess the cumulative effects of sea-level rise and shore erosion on groundwater resources, depending on the predicted climate change scenarios. The results can then help decisionmakers to anticipate the effects of climate change on the groundwater availability in strip oceanic islands and plan future groundwater use accordingly.

Keywords: Climate change, Island hydrology, Groundwater resources, Analytical solutions, Sea-level rise 


\section{Introduction}

Small oceanic islands rely usually more on groundwater resources than surface water resources for the water supply. Ensuring water supply for oceanic island communities is a constant challenge worldwide because oceanic islands are surrounded by seawater that intrudes into the island aquifer. Freshwater contained in island aquifers is represented by a lighter freshwater lens floating above the denser saltwater. This freshwater lens is replenished by precipitation that infiltrates into the subsurface and discharges to the ocean along the island coasts. Oceanic islands can be densely populated considering their attractive environment and the pressure on fresh groundwater resources can be high, making water supply a real challenge, increased by the fact that freshwater is threaten by the surrounding seawater intrusion (Oude Essink, 2001; White and Falkland, 2010; ).

Climate change makes freshwater resources in coastal environments more vulnerable (Melloul and Collin, 2006). One of the consequences of climate change is changes to the pattern and intensity of precipitation, which consequently has an impact on groundwater recharge in aquifers. In addition to the changes in precipitation, two other consequences of climate change that particularly affect coastal environments are sea-level rise and shore erosion (Terry and Falkland, 2010). Both effects amplify 'seawater intrusion' because they result in an inland progression of seawater, often called 'land-surface seawater inundation'. Depending on the climate change scenario, the cumulative effects of freshwater replenishment changes and increased seawater intrusion may have dramatic effects on water supply in oceanic island environments. For this reason, the impacts of climate change on groundwater resources in oceanic island aquifers must be anticipated depending on climate 
change scenarios, in order to help decision makers plan for future possible groundwater use and to make development plans accordingly.

During the last decade, the issue of the impacts of climate change and more specifically of sea-level rise on seawater intrusion in oceanic islands has gained interest worldwide. These impacts have been investigated either with numerical modeling (Sulzbacher et al., 2012; Lemieux et al., 2015; Gulley et al., 2016) or analytical modeling (Ketabchi et al., 2014; Morgan and Werner, 2014; Chesnaux, 2016). However, most of the studies were principally numerical investigations that were conducted for cases of specific islands and their results could not be extended for general cases. Also, except for the study by Lemieux et al. (2015), the combined effects of sea shore erosion and sea-level rise on the characterization of landsurface inundation were not considered, ie only the effects of sea-level rise were investigated.

This study proposes an analytical methodology based on the previous analytical developments of Chesnaux (2016) to investigate the cumulative effects of climate change, i.e. changes in groundwater recharge rate, sea-level rise and sea shore erosion, on freshwater resources in the case of strip oceanic island unconfined aquifers. From this methodology, the effects on both the freshwater lens volume and the annual recharge (freshwater renewal capabilities) can be quantified with different scenarios of climate change. This simple methodology is first presented with the analytical equations to be used and the island hydrogeological information that is required to solve the equations. The methodology is then illustrated with the specific case of a Pacific island located on the West Coast of Canada: Savary Island, British Columbia, when different scenarios of the impacts of climate change are investigated. 
The results obtained from the analytical analysis will be useful to evaluate future freshwater availability and to plan future use of fresh groundwater resources in a sustainable manner. The same methodology could be applied to any case of strip oceanic islands worldwide when the assumptions for the application of the analytical methodology can be made.

\section{Analytical methodology}

Strip islands are elongated islands whose length is significantly greater than their width, with a longitudinal axis of symmetry. The proposed methodology to assess the impacts of climate change on groundwater resources in an oceanic strip-island unconfined aquifer is designed to be conducted in five steps:

1. The first step consists of testing whether the simplified Dupuit-type analytical groundwater flow model of the freshwater lens of the strip oceanic island can be applied to the island that is being considered. For this, it must be verified that the assumptions required by the Dupuit flow-type model are satisfied. Piezometric observations on the island must be available in order to create a piezometric map and to investigate if this map can be fitted to a Dupuit-type flow conceptual model of the island.

2. When the Dupuit-type flow assumptions are verified, the equations developed by Chesnaux (2016) can be used to calculate the change of the volume of the freshwater lens with sea-level rise. Note that before conducting this calculation, the hydrogeological parameters contained in the equation of Chesnaux (2016) must be determined. 
3. The effects of coastal erosion can be included in the Chesnaux (2016) equation in order to obtain a new equation that now combines the effects of sea-level rise and coastal erosion, to determine the global change in the volume of the freshwater lens with climate change.

4. The total loss of recharge of the island with climate change can be calculated from the loss of land due on sea-level rise and coastal erosion combined with the recharge rate that may also evolve with climate change. The predicted values of the loss of recharge can then be compared with the fresh groundwater uptake from the island residents in order to determine if the groundwater exploitation, depending on future scenarios of developments, will not exceed the renewal rate of groundwater resources in a context of climate change

5. Finally, a sensitivity analysis can be conducted on the results of both the changes of the volume of the freshwater lens and the change of total recharge of the lens considering different predicted scenarios of sea-level rise and coastal erosion, as well as recharge rates due on precipitation changes.

\subsection{Dupuit-type groundwater flow model of the strip-island unconfined aquifer}

The steady-state regional flow solution for strip oceanic islands is given in the framework of Dupuit's assumptions (Dupuit, 1863): the island aquifer is unconfined and saturated, homogeneous and isotropic with a hydraulic conductivity represented by a unique value $K$ that is constant. This value can, however, represent an equivalent average value for a system of multi-layered aquifers. The equipotential surfaces are vertical and the velocity is uniform over the entire depth. In the case of oceanic islands, a freshwater lens floats on top of saltwater, such that the interface between the freshwater and saltwater is considered as an 
136 impermeable boundary for freshwater. Also, the aquifer is considered to be uniformly 137 recharged and its discharge into the ocean is represented by a constant head boundary 138 condition. In this study, the closed-form solutions are developed for a constant value of the 139 rate of recharge; but in a context of climate change, recharge rates may also be subject to 140 changes. Lastly in terms of limiting assumptions, the transition zone between the freshwater

141 lens and the saltwater is not taken into account, assuming a sharp interface between 142 freshwater and saltwater.

143 One-dimensional equations for groundwater flow in oceanic islands have been addressed by 144 Fetter (1972). The problem is defined using coordinates $(x, y)$, but the flow is considered 145 horizontal and one-dimensional according to the Dupuit approximation, and indicates that 146 the hydraulic head is dependent only on $x$. The vertical plane, defined by $x=0$, represents 147 the axis of symmetry of the island and also represents the water divide (hydraulic gradient 148 is zero), since the down-gradient boundary is a hydraulic head that is the same on both sides 149 of the island. The length of the island is defined theoretically to be infinite; whereas its half 150 width is $L$ (the total width of the island is $2 L$ ). Due to the symmetry of the island, the problem 151 is solved between $x=0$ to $x=L$ (Figure 1(a)).

152 Figure 1(b) describes the oceanic island system considered. The solution for the 153 elevation of the water table above sea-level, $h(x)$, is given by Fetter (1972), and is expressed 154 as follows:

155

$156 \quad h(x)=\sqrt{\frac{W}{K} \cdot \frac{\Delta \rho\left(L^{2}-x^{2}\right)}{\left(\rho_{\mathrm{f}}+\Delta \rho\right)}}$ 
158 Where $W$ is the recharge rate $\left[\mathrm{LT}^{-1}\right]$ of the aquifer, $K$ its hydraulic conductivity $\left[\mathrm{LT}^{-1}\right], \rho_{\mathrm{f}}$ is

159 the density of freshwater, $\rho_{\mathrm{s}}$ is the density of saltwater, and $\Delta \rho=\rho_{\mathrm{s}}-\rho_{\mathrm{f}}$. Note that the ocean

160 surface is taken as the datum for the heads $h(x)$. Equation (1) was obtained by Fetter by

161 combining Darcy's law and the Ghijben-Herzberg relation (Drabbe and Badon Ghijben,

162 1889; Herzberg, 1901), giving the position of the freshwater/saltwater interface. This latter

163 relation is written as follows (Equation (2)):

164

$165 \quad z(x)=\frac{\rho_{\mathrm{f}}}{\rho_{\mathrm{s}-} \rho_{f}} \cdot h(x)=\frac{\rho_{\mathrm{f}}}{\Delta \rho} \cdot h(x)$

166

where $h(x)$ is the elevation of the water table above sea-level, and $z(x)$ is the depth to the

168 fresh-saline interface below sea-level.

169

170

171

172

173

174

175

176

177

178

$179 \quad V_{t}=\frac{\pi n_{e}}{2} \sqrt{\frac{W}{K}\left(1+\frac{\rho_{f}}{\Delta \rho}\right) \cdot} L_{t}^{2}$ 
181 with $n_{e}$ the effective porosity of the aquifer.

182 The volume of the lens will change with $L_{t}$ and, in a context of climate change, $L_{t}$ will 183 diminish with the effects of both sea-level rise and coastal erosion.

\subsection{Land-surface inundation: Sea-level rise and coastal erosion}

186 Sea-level rise and coastal erosion are parameters that must be predicted by climatic models. The rates of sea-level rise and coastal erosion will be used to determine the change in the strip island width, which is represented by the variation of $L_{t}$ with time (Figure 1(b)).

\subsubsection{Sea-level rise}

191 Let's define $S_{t}$ to be the sea-level at time $t$ and $\Delta S_{t}$ to be the change of sea-level over time $t$ :

$192 \Delta S_{t}=S_{t}-S_{0}$ with $S_{0}$ and $S_{t}$ the initial sea-level and the final sea-level after time $t$, respectively.

193 If $\Delta S_{t}>0$, sea-level has risen during $t$ and conversely if $\Delta S_{t}<0$, sea-level has dropped during

$194 t$. A change of $S\left(\Delta S_{t}\right)$ over time $t$ will cause a change of $L\left(\Delta L_{t}=L_{t}-L_{0}\right)$ over time $t$ depending 195 on $\theta$, the slope (angle of the shore face compared to the horizontal) of the island aquifer 196 (Equation (4)):

197

$198 \frac{\Delta S_{t}}{\Delta L_{t}}=-\tan \theta$

200 The resulting inundation of the strip island in the case of sea-level rise $\Delta S_{\text {SLR }}$ during $t$ is of $201 \Delta L_{S L R}=-\Delta S / \tan \theta$ as $\Delta L_{S L R}$ is negative and $\Delta S$ positive. 
224

\subsubsection{Coastal erosion}

While sea-level rise is usually considered to represent the main impact of climate change on coastal aquifers, other impacts such as coastal erosion can also be expected. Coastal erosion will diminish the width of islands and the erosion rate can be noted as $\Delta L_{C E}$. This erosion rate corresponds to the loss of coastal land ( $\triangle L_{C E}$ is negative) during a given period of time. Usually, erosion is expressed as a length of width of coast lost per year. This loss will cause the progression of seawater into the land, having comparable effects of sea-level rise. Indeed, both sea-level rise and erosion lead to land-surface inundation.

\subsubsection{Total land-surface inundation}

The total land-surface inundation, noted as $\Delta L$ (negative value), due to climate change expresses the total loss of land due on the combination of sea-level rise $\left(\Delta L_{S L R}\right)$ and coastal erosion $\left(\Delta L_{C E}\right) \cdot \Delta L$ can therefore be expressed as (Equation (5)):

$$
\Delta L=\Delta L_{S L R}+\Delta L_{C E}=-\Delta S / \tan \theta+\Delta L_{C E}
$$

\subsection{Changes in freshwater lens volume}

After there is a change of the width of the island with climate change over time $t$, the consecutive change in the volume $\Delta V$ of the freshwater lens can be determined by using Equation (3) to yield Equation (6):

$$
\Delta V=V_{t}-V_{0}=\frac{\pi n_{e}}{2} \sqrt{\frac{W}{K}\left(1+\frac{\rho_{f}}{\Delta \rho}\right)} \cdot\left(L_{t}^{2}-L_{0}^{2}\right)=\frac{\pi n_{e}}{2} \sqrt{\frac{W}{K}\left(1+\frac{\rho_{f}}{\Delta \rho}\right)} \cdot \Delta L \cdot\left(\Delta L+2 L_{0}\right)
$$


226 Combining Equations (5) and (6) gives an expression of the change of volume of the 227 freshwater lens (per unit length of the strip island) with sea-level rise and erosion (Equation $228(7))$ :

$\Delta V=\frac{\pi n_{e}}{2} \sqrt{\frac{W}{K}\left(1+\frac{\rho_{f}}{\Delta \rho}\right)} \cdot\left(\Delta L_{C E}-\frac{\Delta S}{\tan \theta}\right) \cdot\left(\Delta L_{C E}-\frac{\Delta S}{\tan \theta}+2 L_{0}\right)$

Equation (7) is the closed-form solution for calculating the change of volume of the freshwater lens in a strip oceanic island as a function of the initial half-width $L_{0}$ of the island and the slope $\theta$ of the coast when sea-level rises by $\Delta S$ and when coastal erosion (loss of width of the island) is $\Delta L_{C E}$. Note that $\Delta V$ is per unit length of island and that its value is negative.

Equation (7) depends on the recharge rate $W$ that can also change over time with climate change and it can be observed that the change of volume is directly proportional to the root square of the rate of recharge.

\subsection{Groundwater total recharge}

Groundwater recharge rates $W_{t}\left[\mathrm{LT}^{-1}\right]$ may change with climate change over time $t$ on the one hand but on the other hand the total recharge, noted $R_{t}$, will diminish with climate change due on the loss of land surface (land surface inundation). The total groundwater recharge of the freshwater lens $R_{t}\left[\mathrm{~L}^{2}\right]$ at time $t$ during a period of time $\Delta t$ per unit length of the strip island corresponds to the recharge rate $W$ during the period of time $\Delta t$ multiplied by the surface of the strip island of width $2 L_{t}$ at time $t$ per unit length of the island (Equation (8)): 
251 The value of the total recharge $R_{t}$ during a period of time $\Delta t$ indicates the amount of 252 freshwater that is renewed in the lens during $\Delta t$. This amount theoretically corresponds to 253 the amount of water that can be tapped in the lens without depleting the resource (the rate of 254 uptake should not exceed the rate of renewal). Consequently, characterizing the value of $R_{t}$ 255 in a context of climate change is of crucial interest and importance for decision-makers since 256 it corresponds to the maximum value of fresh groundwater that can be exploited in the lens 257 during a period of time $\Delta t$.

$258 R_{t}$ represents a threshold value when planning on future scenarios of possible water use when 259 one includes the effects of climate change on both land inundation and groundwater recharge 260 rates.

\section{Illustration with a case study: example of Savary Island, Canada}

\subsection{Description of Savary Island and its hydrogeological features}

Savary Island is a long and narrow oceanic island on the Pacific coast of British Columbia, Canada, measuring approximatively $7.5 \mathrm{~km}$ long in an east-west direction and 0.6 to $0.8 \mathrm{~km}$ wide in a north-south direction. It can be considered as a strip island, with the initial assumption that it satisfies the conditions for the application of the Dupuit approximation on the freshwater lens of the island (this assumption will be verified in this study, based on the results obtained from the interpolation of the water table elevations).

271 Savary Island is exposed to the consequences of climate change, including sea-level rise 
combined with an intense erosion of its coast. For these reasons, Savary Island offers the typical and representative conditions to illustrate the methodology proposed in this study, to quantify the consequences of climate change for strip oceanic islands.

The mean shore slope of the island is $40 \mathrm{~m} / \mathrm{km}$. Savary Island is located $150 \mathrm{~km}$ north-west of Vancouver and the island is populated with 100 permanent inhabitants whereas it can be populated with 500 inhabitants during the summer season since it is very attractive to tourism. The island relies on only its fresh groundwater lens for water supply (domestic use only). Savary Island is composed mainly from sand (known as Quadra sand) deposited by glaciers during the Pleistocene. This sand deposit forms an aquifer, for which the mean hydraulic conductivity has been determined with a pumping test: average $K=5 \times 10^{-5} \mathrm{~m} / \mathrm{s}$ (Thurber Engineering Ltd., 2003). Homogeneous and isotropic conditions can be considered for this aquifer. The effective porosity $n_{e}$ of the aquifer is 0.3 . The island receives an average of 1,100 mm precipitation per year from which $23 \%$ is recharge for the aquifer, making $W$ equal to $250 \mathrm{~mm} / \mathrm{year}$ (Pacific Hydrology Consultants LTD., 1987). A groundwater well database is available and contains information for 48 domestic wells (British Columbia Government, 2020); the British Columbia Water Resources Atlas is a GIS based system that provides aquifer maps and water well information (stratigraphy, static water levels and specific capacity tests). Figure 2 shows a map of Savary Island with the digital elevation model (DEM) based on LiDAR data and the locations of the domestic wells. Figure 2 shows that the distribution of the domestic wells is not uniform, with most of the wells located in the western and eastern parts of the island where urban development is found. 
Regarding the scenarios of sea-level rise and coastal erosion, a constant rate of sea-level rise of $0.7 \mathrm{~mm} /$ year (for the next 100 years) was selected as proposed by Forbes et al. (2004) and a constant average rate of coastal erosion of $0.2 \mathrm{~m} /$ year, specifically for Savary Island, has been considered according to Thurber Engineering Ltd. (2003).

\subsection{Results}

It is first verified that the Dupuit model can be applied to the groundwater system of Savary Island based on the piezometric map of the freshwater lens of the island. Once the Dupuit flow model is verified, the equations for assessing the impacts of climate change are then applied to draw conclusions on the consequences of climate change for the next 100 years.

\subsubsection{Flow model: interpolated hydraulic heads in the aquifer of Savary Island}

The piezometric data at the 48 wells are included in the well database used to create the piezometric map of Savary Island (Figure 3). Water levels $h(x)$ corresponding to elevation of the water table above sea level are interpolated considering a quadratic relationship of the squared hydraulic heads and the spatial distance according to Equation (1) when the Dupuit assumptions are considered for the flow model. Note that the application of the Dupuit assumption is later verified with the constant parameters of the regression equation obtained from the interpolation. Figure 3 shows the interpolated water table position map (or piezometric map) of the Savary Island freshwater lens aquifer. Interpolation was realized using the ArcGIS software. Note that the piezometric map was generated only for the western part of the island, where there were sufficient observation wells (used to constrain the interpolation of the water levels) with a satisfying density and distribution (see Figure 2) to apply the interpolation of the piezometric observations in the wells. 
The interpolated water-table-elevation profile $h(x)$ obtained along cross section A-A' of Figure 3 is shown in Figure 4. The freshwater lens thickness, which equals $h(x)+z(x)$, is calculated from Equation 2 with the $h(x)$ interpolated values and is represented in Figure 4. Note that the cross section A-A' has a length (equal to $2 L)$ of $660 \mathrm{~m}(L=330 \mathrm{~m})$.

By plotting the squared water table elevation $\left(h^{2}\right)$ as a function of $x$ (along cross section AA' with $x=0$ centered on A-A'), a second degree polynomial relationship is obtained since a quadratic interpolation was applied to generate the water table elevation map satisfying the Dupuit-Forchheimer theory (Equation 1). After applying the quadratic regression to $h^{2}$ vs. $x$, the resulting equation is written as: $h^{2}=-5 \times 10^{-6} x^{2}+0.53$ with $h$ and $x$ expressed in meters (Figure 5).

Therefore, the constant $(\Delta \rho \times W / K) /(\rho+\Delta \rho)$ in Equation 1 equals $5 \times 10^{-6}$. With $\rho$ (density of freshwater) equal to 1 and $\Delta \rho$ equal to 0.25 , it follows that $W / K$ is equal to $2 \times 10^{-4}$. Comparing this value obtained from applying the Dupuit model of the freshwater lens of Savary Island with the observed value of $W / K$ allows one to evaluate the validity of applying the Dupuit model for Savary Island. With a recharge value of $250 \mathrm{~mm} / \mathrm{y}\left(\right.$ i.e. $\left.8 \times 10^{-9} \mathrm{~m} / \mathrm{s}\right)$ and a hydraulic 
344 conductivity value of $5 \times 10^{-5} \mathrm{~m} / \mathrm{s}$, it follows that $W / K$ is equal to $1.6 \times 10^{-4}$. This value is very

345 close to the value of $2 \times 10^{-4}$ obtained from the Dupuit model. Such a small difference shows

346 that the hydrogeological conditions on Savary Island allow the application of the Dupuit

347 model from which the analytical solutions for assessing the consequences of climate change

348 can be determined as presented earlier.

3.2.2 Impacts of climate change: variations of the volume of the freshwater lens and of the

351 total recharge

352 The future impacts of climate change on the groundwater resources in Savary Island are

353 calculated with Equations (7) and (8) taking into account the cumulative effects of sea-level

354 rise and coastal erosion. Table 1 summarizes the parameters and the mean values that are

355 considered to solve the equations in the specific case of Savary Island.

357 Table 1. Input parameters considered for the case of Savary Island.

\begin{tabular}{|l|l|}
\hline Parameter & Value \\
\hline$L_{0}$ (Initial average half-width of Savary Island, $\left.\mathrm{m}\right)$ & 330 \\
\hline Total length of Savary Island $(\mathrm{m})$ & 7,500 \\
\hline Average shore slope $(\mathrm{m} / \mathrm{km})$ & 40 \\
\hline Tan $\theta$ & 0.04 \\
\hline Hydraulic conductivity $K(\mathrm{~m} / \mathrm{s})$ & $5 \times 10^{-5}$ \\
\hline Annual recharge rate $W(\mathrm{~mm} / \mathrm{y})$ & 250 \\
\hline Effective porosity $n_{\mathrm{e}}$ & 0.3 \\
\hline Mean annual sea-level rise $(\Delta S$ per year, $\mathrm{m} / \mathrm{y})$ & 0.007 \\
\hline
\end{tabular}




\begin{tabular}{|l|l|}
\hline Mean coastal erosion rate $\left(\Delta L_{\mathrm{CE}}\right.$ per year, $\left.\mathrm{m} / \mathrm{y}\right)$ & 0.2 \\
\hline
\end{tabular}

The initial total volume (present volume at initial time) of the freshwater lens is calculated by $V_{0}=\frac{\pi n_{e}}{2} \sqrt{\frac{W}{K}\left(1+\frac{\rho_{f}}{\Delta \rho}\right)} \cdot\left(L_{0}^{2}\right) \cdot 7,500$ and is equal to $\sim 31$ million $\mathrm{m}^{3}$.

The changes in the total freshwater lens volume $\Delta V$ are calculated for the next 100 years from an annual basis using Equation (7). The results are presented in Figure 6 where the effects of sea-level rise on the one hand and the effects of coastal erosion on the other hand can be visualized.

In the example presented in Figure 6, the respective effects of sea-level rise and coastal erosion on the decrease of the volume of the freshwater lens are comparable, with coastal erosion having an effect slightly greater than sea-level rise. In total, after 100 years, it can be observed that the freshwater lens volume will have diminished by more than $22 \%$ due to climate change (freshwater lens volume to be $\sim 24.4$ million $\mathrm{m}^{3}$ in 2120 whereas it is $\sim 31$ million $\mathrm{m}^{3}$ in 2020). Note that the recharge rate has been considered to be fixed at $W=250$ $\mathrm{mm} / \mathrm{y}$ but this rate may also evolve with climate change and the calculations conducted with Equation (7) could be conducted accordingly when considering variable values of $W$. This 376 is the same for the rates of sea-level rise and coastal erosion that have been taken to be 377 constant for the next century; these rates could evolve over time and could be changed accordingly. A further sensitivity analysis could be conducted from Equation (7) when changing the values of the different parameters. 
A last analysis of the impacts of climate change on Savary Island's groundwater resources consists of assessing the renewable volumes of the total groundwater recharge in the island, to be calculated from Equation (8). This total recharge to be defined over a period of time defines the amount of freshwater that could potentially be extracted without depleting the freshwater lens. The total recharge over a period of time, expressed in Equation (8), defines the total flux of infiltrated freshwater flowing through the lens, from recharge with rainwater to discharge to the ocean. Today, the total recharge for year 2020 calculated from Equation (8) is 1.24 million $\mathrm{m}^{3}$ with $L_{0}=330 \mathrm{~m}$. Considering that 100 inhabitants currently live permanently on Savary Island and that they consume $\sim 350 \mathrm{~L}$ per day and per inhabitant, the total amount of freshwater tapped each year in the freshwater lens is $\sim 13,000 \mathrm{~m}^{3}$. This volume of consumed freshwater consequently corresponds to $\sim 1 \%$ of the renewable annual rate of freshwater of the island. This value of $1 \%$ is low but it should be reminded that this is a minimal rate because the population of the island can increase to several hundreds when including the visitors during the summer season. In 100 years, with the predicted effects of climate change using Equation (5), that considers both effects of sea-level rise and coastal erosion, the land-surface inundation is calculated to be $37.5 \mathrm{~m}$, from which $17.5 \mathrm{~m}$ of land loss will be due on sea-level rise and $20 \mathrm{~m}$ of land loss will be due to erosion. The new mean value of half-width of the island after 100 years, $L_{100 y}$, will therefore be $292.5 \mathrm{~m}$. Applying Equation (8) to this new value of $L$ yields a total annual recharge of 1.1 million $\mathrm{m}^{3}$ for year 2120 if the recharge rate $W$ is considered unchanged. This new value of total recharge is to be compared with the value of 1.24 million $\mathrm{m}^{3}$ for today, in 2020 , and shows a decrease of more than $11 \%$ of the groundwater transiting in the lens. If the population is unchanged in 100 years (still 100 inhabitants on Savary Island), then the water consumption will 
403

404

405

406

407

408

409

410

411

412

413

414

415

416

417

418

419

420

421

422

423

424

correspond to a new value of $1.16 \%$ of the renewable annual rate of freshwater of the island in 2120 , ie an increase of $0.16 \%$ on the previous rate of 2020 .

\section{Discussion and conclusion}

The proposed methodology to assess the impacts of climate change in the strip oceanic island of Savary Island could be extended to any strip oceanic island worldwide when it can be verified that Dupuit flow assumptions apply to groundwater flow in the freshwater lens. From the proposed equations and considering Dupuit assumptions, both the effects of climate change on sea-level rise and coastal erosion can be evaluated on the change of volume of the freshwater lens on the one hand and on the change of total recharge in the island on the other hand. Considering the uncertainties that exist both on the hydrogeological parameters of the island and on the predicted scenarios of climate change, sensitivity analysis can be conducted from the proposed equations to determine different possible scenarios as a function of the values of the parameters involved in the predictions. The accuracy of the predictions not only depends on the accuracy of the climate prediction models, but also on the accuracy of the hydrogeological model. The results obtained for the impacts on fresh groundwater resources strongly depend on the strength and reliability of the climate models.

The uncertainties relating to coastal erosion values represent a limitation of the predicting model. Indeed, a uniform sea-level rise may lead to a non-uniform coastal erosion of the shore; for this reason, considering a mean coastal erosion rate may be a limiting assumption. It should be noted that the rate of recharge may vary with climate change. This variation should be predicted and taken into account in the equations, in addition to sea-level rise and 
425

426

427

428

429

430

431

432

433

434

435

436

437

438

439

440

441

442

443

444

445

446

447

coastal erosion, when assessing the impacts of climate change on fresh groundwater resources.

The protection of the shore against coastal erosion could lower the impacts of climate change on inland inundation. Land reclamation could also be considered to reduce the impacts of sea-level rise and coastal erosion, since the reclamation mitigates the effects of loss of land due to erosion and coastal inundation.

The proposed equations may prove to be useful to not only predict how island fresh groundwater resources will deplete with climate change but also to manage future groundwater use in regards to available resources in a context of increase of coastal and island populations. Although the proposed model requires one to consider assumptions that simplify the reality, it remains that the proposed equation can still give a first estimate of the impacts of climate change. Finally, the advantage of using a simplified model and simple closed-form analytical solutions is that practitioners and decision makers can easily include the solutions in their toolbox with very limited costs.

\section{Acknowledgements}

The authors acknowledge the financial support of the Groupe de recherche Risque Ressource Eau (R2eau) at Université du Québec à Chicoutimi (UQAC) as well as the Natural Sciences and Engineering Research Council (NSERC - federal funding) of Canada in the framework of the Individual Discovery Grant Program held by Prof. Romain Chesnaux. The Qathet Regional District of British Columbia and Mr. Caleb Allen are acknowledged for providing the digital elevation model (DEM) of Savary Island. Ms. Josée Kaufmann and Ms. Sue Duncan are thanked for editorial collaboration. 


\section{References}

450 British Columbia Government 2020. BC Water Resources Atlas: 451 https://maps.gov.bc.ca/ess/hm/wrbc/, accessed December 12 ${ }^{\text {th }}, 2020$.

Chesnaux, R. 2016. Closed-form analytical solutions for assessing the consequences of sea-

454 455

456

457

458

459

460

461

462

463

464

465

466

467

468

469

470

471

Drabbe, J. and Badon Ghijben, W., 1889. Nota in verband met de voorgenomen putboring nabij Amsterdam (Note in connection with the intended well drilling near Amsterdam). Tijdschrift van het Koninklijk Instituut Van Ingenieurs 1888-1889, 8-22.

level rise on unconfined sloping island aquifers. Global and Planetary Change 139: 109115.

Dupuit, J. 1863. Étude théorique et pratique sur le mouvement des eaux dans les canaux découverts et à travers les terrains perméables (Theoretical and practical study of the movement of water in open canals and through permeable terrain). 2nd ed. Paris, France: Dunod.

Fetter Jr. C.W. 1972. Position of the saline water interface beneath oceanic islands. Water Resources Research 8(5): 1307-1315.

Forbes, D.L., Parkes, G.S., Manson, G.K., Ketch, L.A. 2004. Storms and shoreline retreat in the southern Gulf os St. Lawrence. Marine Geology 210: 169-204. 
472 Gulley, J.D., Mayer, A.S., Martin, J.B., Bedekar, V. 2016. Sea-level rise and inundation of 473 island interiors: Assessing impacts of lake formation and evaporation on water resources in 474 arid climates. Geophysical Research Letters 43(18): 9712-9719.

475

476 Herzberg, A. 1901. Die Wasserversorgung einiger Nordseebaden (The water supply of the 477 North Sea baths). Zeitung Gasbeleuchtung und Wasserversorgung (Journal of Gas Lighting 478 479 480 481 482 483 484 485 486 487 488 489 490 491 492 493

494 Oude Essink, G.H.P. 2001. Improving fresh groundwater supply-problems and solutions. 495 and Water Supply) 44: 815-819.

Ketabchi, H., Mahmoodzadeh, D., Ataie-Ashtiani, B., Werner, A.D., Simmons, C.T. 2014. Sea-level rise impact on fresh groundwater lenses in two-layer small islands. Hydrological Processes 28(24): 5938-5953.

Lemieux, J.-M., Hassaoui, J., Molson, J., Therrien, R., Therrien, P., Chouteau, M., Ouellet, M. 2015. Simulating the impact of climate change on the groundwater resources of the Magdalen Islands, Québec, Canada. Journal of Hydrology: Regional Studies 3: 400-423.

Melloul, A. and Collin, M. 2006. Hydrogeological changes in coastal aquifers due to sealevel rise. Ocean \& Coastal Management 49: 281-297.

Morgan, L.K. and Werner, A.D. 2014. Seawater intrusion vulnerability indicators for freshwater lenses in strip islands. Journal of Hydrology 508: 322-327.

Ocean \& Coastal Management 44: 429-449. 
497 Pacific Hydrology Consultants LTD., 1987. A review of the groundwater situation in Savary 498 Island, 26 pages.

499

500 Sulzbacher, H., Wiederhold, H., Siemon, B., Grinat, M., Igel, J., Burschill, T., Günther, T., 501 Hinsby, K. 2012. Numerical modelling of climate change impacts on freshwater lenses on 502 the North Sa Island of Borkum using hydrological and geophysical methods. Hydrology and 503 Earth System Sciences 16: 3621-3643.

504

505 Terry, J.P. and Falkland, A.C. 2010. Responses of atoll freshwater lenses to storm-surge 506 overwash in the Northern Cook Islands. Hydrogeology Journal 18: 749-759.

507

508 Thurber Engineering Ltd. 2003. Savary Island dune and shoreline study, Report to the 509 Powell River Regional District. File: 14-197-0, 40 pages.

510

511 White, I. and Falkland, T. 2010. Management of freshwater lenses on small Pacific islands. $512 \quad$ Hydrogeology Journal 18: 227-246.

513 
516

517 Figure 1 (a): Cross-section of the hydrogeological conceptual model in a strip-island 518 unconfined aquifer (left hand side) and (b) Effects of sea-level rise and coastal erosion (right 519 hand side).

520

521

522

523

524

526

527

528

529

530

531 Island.

532

533

534

535

536

\section{FIGURE CAPTIONS:}

Figure 2: Location of Savary Island, digital elevation model (DEM) and locations of the domestic wells.

Figure 3: Interpolated observed water-table elevations in the western part of Savary Island. The water-table elevations are expressed in meters above sea level.

Figure 4: Digital elevation model (DEM), water table profile and saltwater/freshwater transition zone modeled along the cross section A-A' according to the Dupuit model.

Figure 5: Interpolated squared saturated thickness $\left(h^{2}\right)$ along cross section A-A' in Savary Island.

Figure 6: Prediction of the variation of volume of the freshwater lens of Savary Island with sea-level rise and coastal erosion for the next 100 years. 


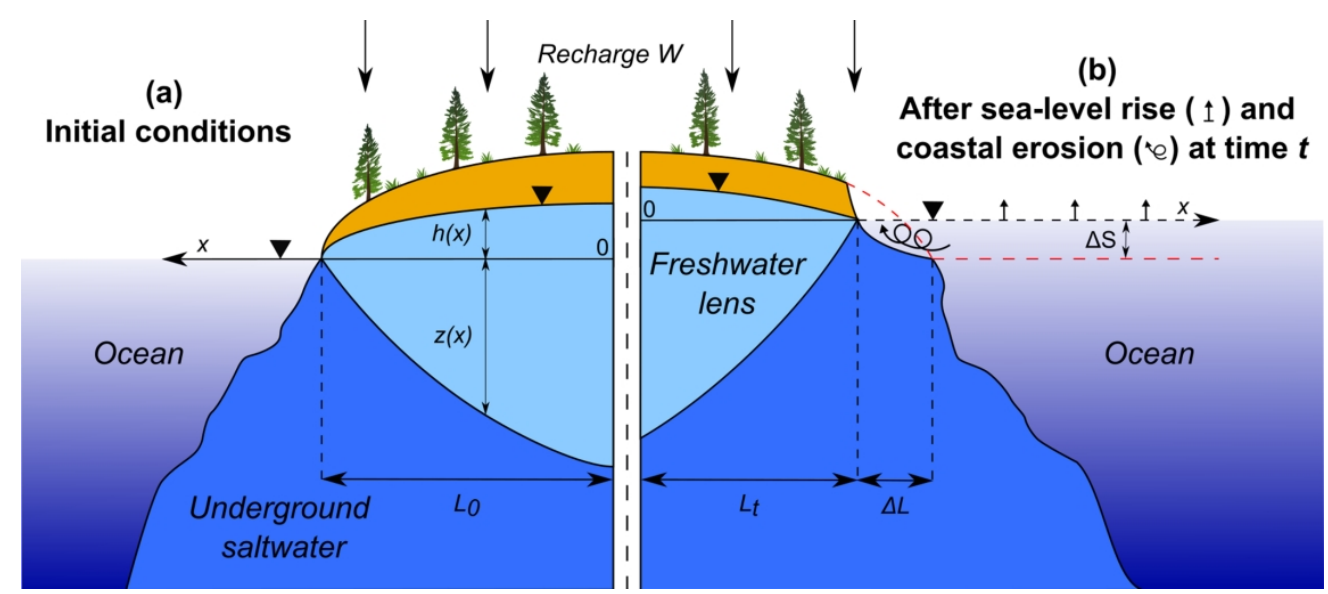

Figure 1 (a): Cross-section of the hydrogeological conceptual model in a strip-island unconfined aquifer (left hand side) and (b) Effects of sea-level rise and coastal erosion (right hand side). 


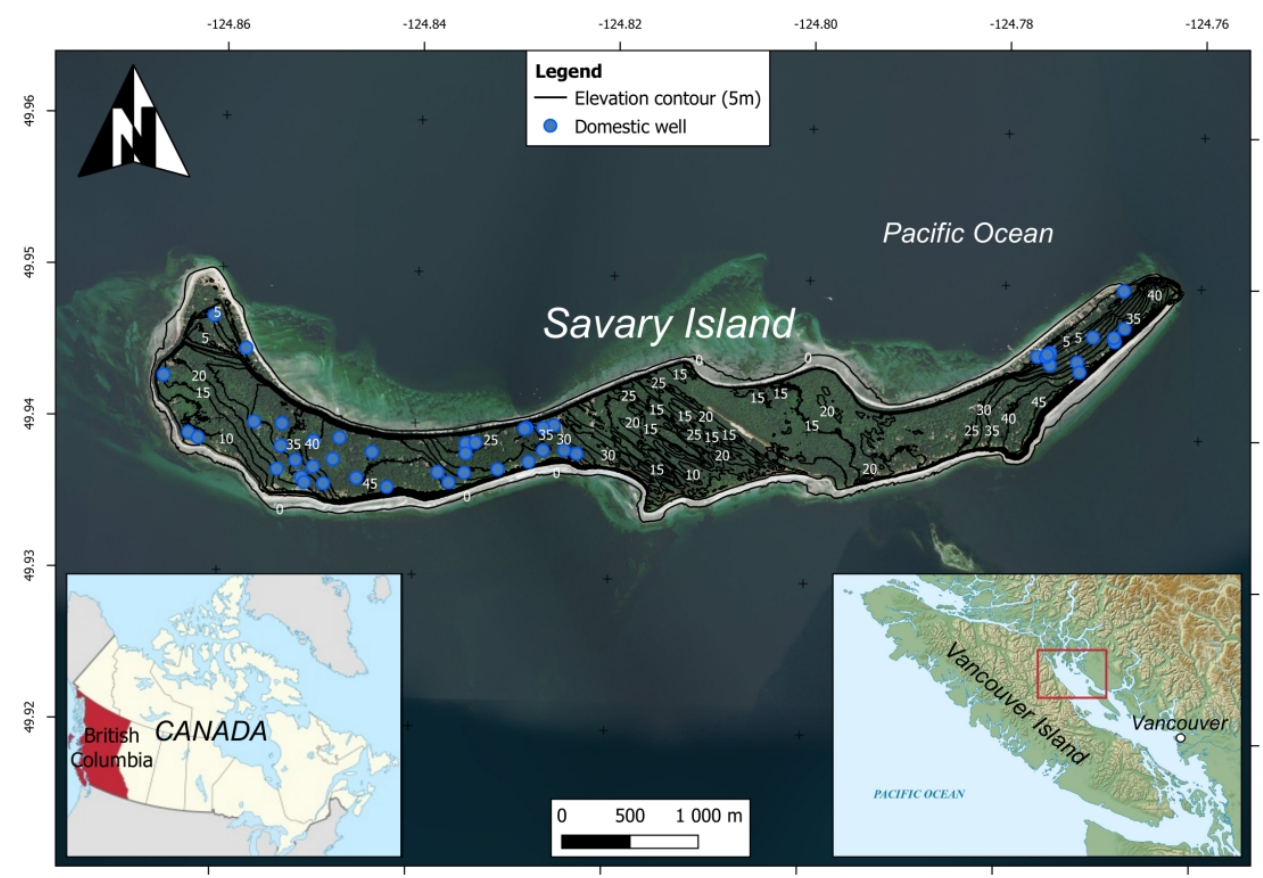

Figure 2: Location of Savary Island, digital elevation model (DEM) and locations of the domestic wells. $825 \times 583 \mathrm{~mm}(72 \times 72 \mathrm{DPI})$ 


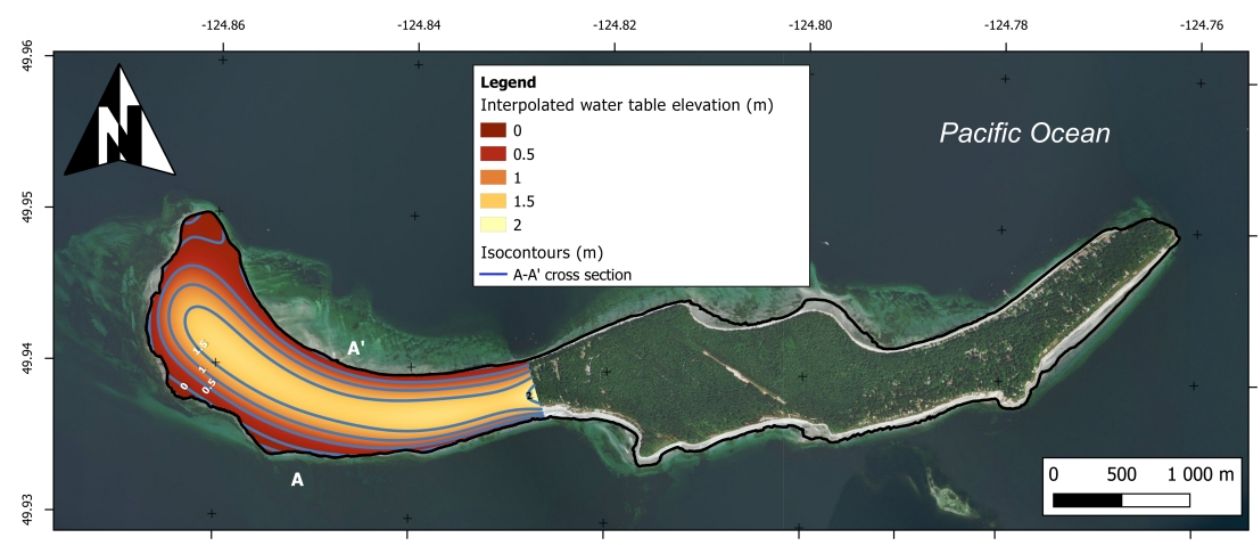

Figure 3: Interpolated observed water-table elevations in the western part of Savary Island. The water-table elevations are expressed in meters above sea level 


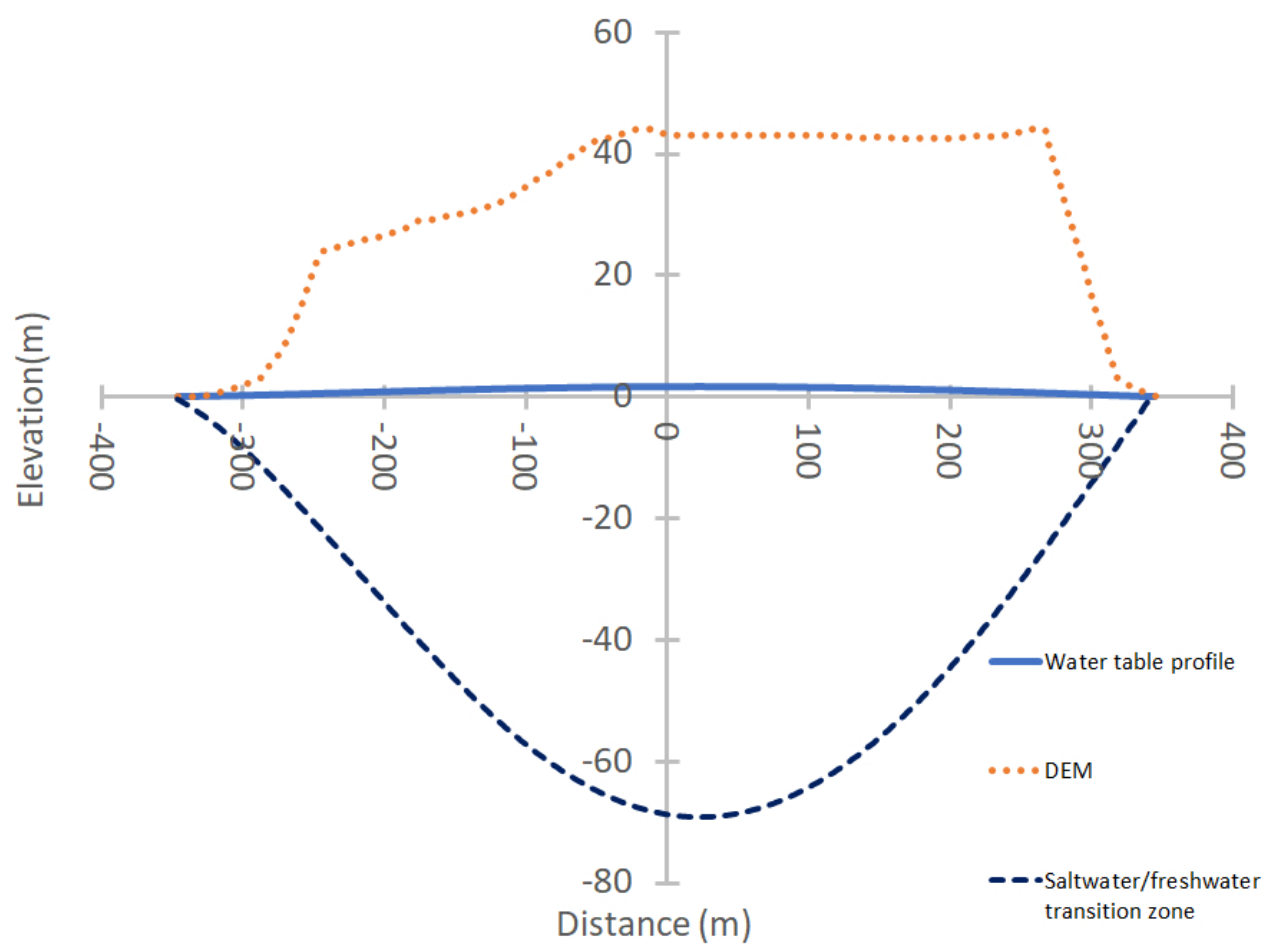

Figure 4: Digital elevation model (DEM), water table profile and saltwater/freshwater transition zone modeled along the cross section $\mathrm{A}-\mathrm{A}^{\prime}$ according to the Dupuit model.

$240 \times 174 \mathrm{~mm}(96 \times 96 \mathrm{DPI})$ 


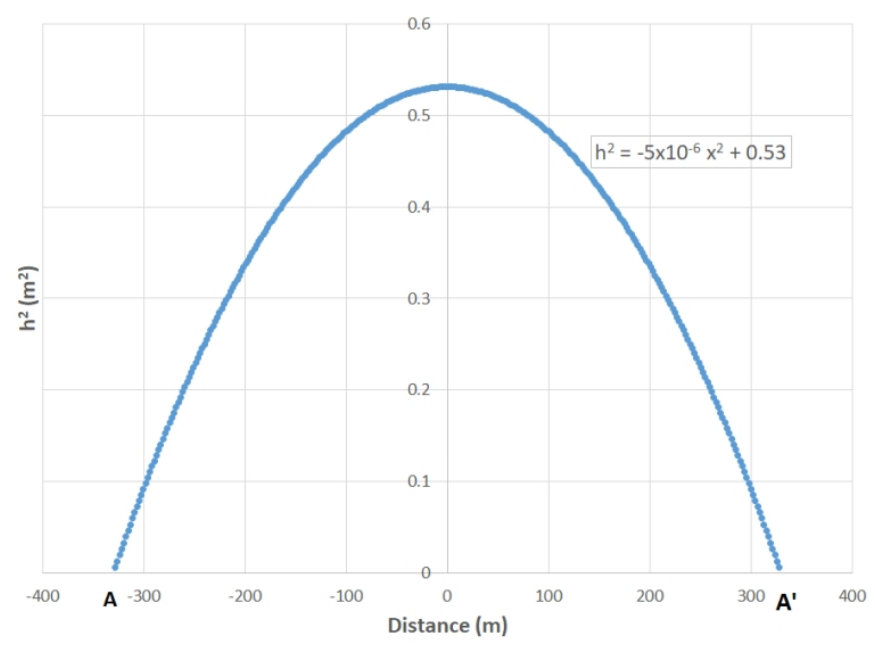

Figure 5: Interpolated squared saturated thickness (h2) along cross section A-A' in Savary Island.

$357 \times 174 \mathrm{~mm}(96 \times 96 \mathrm{DPI})$ 


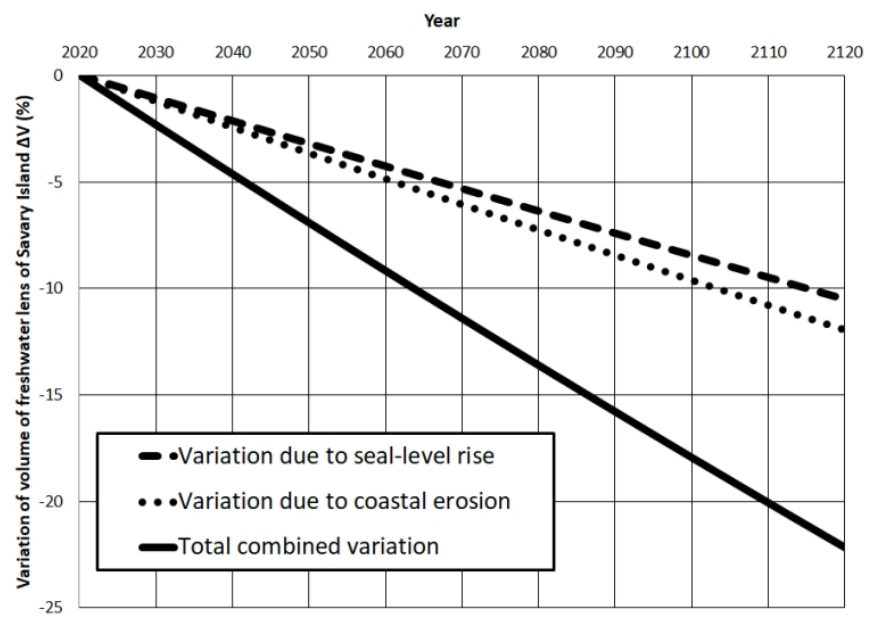

Figure 6: Prediction of the variation of volume of the freshwater lens of Savary Island with sea-level rise and coastal erosion for the next 100 years.

$357 \times 174 \mathrm{~mm}(96 \times 96$ DPI) 